\title{
Supporting User Participation in Local Policy Development: The Fife Dementia Strategy
}

\author{
Louise McCabe* and Brittany Ellis Bradley** \\ * Dementia Services Development Centre, University of Stirling \\ E-mail: louise.mccabe@stir.ac.uk \\ **Warwick Medical School, University of Warwick \\ E-mail: BrittanyJEllis@gmail.com
}

This article reviews the consultation process during the development of a local dementia strategy. The processes of involvement by the range of stakeholders involved and how their different views shaped the strategy are considered. Particular attention is paid to the involvement of people with dementia as they are the recipients of the services to be shaped by the strategy and also form the group most difficult to reach. This article demonstrates the value of including a wide range of stakeholders in the development of local policy and the importance of involving people with dementia in policy development.

Keywords: Citizenship, older people, user involvement, care services.

\section{Introduction}

Currently there is a drive to develop 'dementia strategies' at a national level. So far many countries including England, Scotland, France and Norway have developed strategies with others in the process of doing so (for example see Norwegian Ministry of Health and Care Services, 2008; DH, 2009a). These strategies share the common aim of improving the lives of people with dementia and their carers through developments in treatment, care and support. In parallel to these national strategies, there has been the development of local strategies, such as the Fife Dementia Strategy discussed in this article. This strategy reflects many aspects of the national strategies, but has a more practical and operational approach to enable its implementation in Fife. Fife is a large local authority area in the east of Scotland with a mix of rural and small urban areas. Currently in Fife there are an estimated 5,700 people with dementia, but this is predicated to rise to 11,000 by 2030 (Reynish, 2009).

The Fife strategy was developed in partnership between NHS Fife, Fife Council social work services and the Dementia Services Development Centre, University of Stirling through a knowledge transfer partnership (KTP) scheme. The strategy was driven by service managers within health and social work looking to improve dementia care across Fife and to plan for future increases in numbers of people with dementia. It is also likely they were influenced by growing recognition by national governments in the UK of the need for improved dementia care. They lobbied support from policy makers in the region and sought out funding through the KTP scheme to take their plan forward. The authors of this paper were both directly involved in the strategy development and are the academic 
partner and the KTP associate, the individual tasked with the everyday work of developing the strategy.

This article focuses on the consultation process that took place prior to publication of the strategy. This consultation process encouraged participation from a wide range of stakeholders, including people with dementia, informal carers and other people using the same services. The role of people with dementia and other service users in user consultation processes is highlighted.

User involvement in policy and service development has been a stated aim for well over a decade and continues to be promoted in policy, as illustrated by policy titles such as the 2009 Green Paper, Shaping the Future of Care Together (HM Government, 2009). Carey (2009) recognises that user involvement in the UK has developed rapidly in recent years and has produced a new culture where users are encouraged to participate. There are many examples of successful user involvement in the development of, for example, social work education (Agnew and Duffy, 2010) and clinical guidelines (Gould and Kendall, 2007) and many different approaches taken. Service users may be recruited by policy makers and asked to comment on services or strategies as in this project; or service users themselves may seek opportunities for participation such as the work of the Scottish Dementia Working Group discussed below. However, Carey (2009) critiques user and carer participation in its current forms, arguing that these current forms may better support governmental and organisational agendas rather than giving service users real power to influence change. Beresford (2010) presents the views of service users on the process of user involvement and finds that their interests more often lie in forming alliances between user groups rather than partnerships with public bodies.

The current drive towards personalisation in adult social care (Scottish Government, 2009; DH, 2010) would seem to increase the involvement of service users in the design and delivery of their own care and support by giving them personal control over the services and support that they receive. However, it is not yet clear how well self-directed support will work for people with dementia and it may be that there are specific barriers for people with dementia in taking up these types of support.

\section{Involving people with dementia}

Historically, people with dementia were heard through their carers or professionals and practitioners. However, it is now appreciated that the perspectives of people with dementia and their carers should be seen as distinct to ensure that people with dementia are not disempowered (Gould and Kendall, 2007).

The voices of people with dementia are increasingly heard both in research and in the policy field. Over the past ten years, research that directly engages with people with dementia has grown significantly. There have also been a number of publications written by people with dementia themselves offering unique insights into the condition (e.g. DeBaggio, 2002; Mobley, 2007). People with dementia have given their views and related their experiences on many different aspects of their lives. Clare and colleagues have explored the concepts of insight and awareness of people with dementia at the point of diagnosis through to residential care (Clare, 2002; Clare et al., 2005; Clare et al., 2008a). The views of people with dementia have been sought on the process of assessment and diagnosis (Keady and Gilliard, 2002; Langdon et al., 2007; Keady et al., 2009); their 
experiences living at home following diagnosis (Macquarrie, 2005; Steeman et al., 2007; Beard and Fox, 2008; Alzheimer's Society, 2009); their experiences at day care (Reid et al., 2001); and their experiences and views of residential care (Graneheim and Jansson, 2006; Ward et al. 2008; Clare et al., 2008b). However, these voices are, obviously, drawn from people willing and able to take part in research; but it is often the case that people with dementia who present a challenge for us to hear are not included in research. How advanced an individual's dementia is will impact on whether they are asked to take part in research and their ability to do so. The findings from research present a varied and rich picture of the lives of people with dementia. They also provide valuable information for service planners and policy makers. The direct involvement of people with dementia in policy is also increasing as the following discussion illustrates.

The NICE/SCIE (2006) guidelines regarding dementia provide guidance for best practice in the treatment and care of people with dementia. Gould and Kendall (2007) reflect on the process of development of these guidelines and describe the participation of people with dementia and their carers. The main work developing the guidelines was done by a group of health and social care professionals, lay representatives, technical expects, two carers and one person with dementia. Gould and Kendall (2007) report that the person with dementia was able to participate fully throughout the guideline development process and that this individual also contributed to evaluating evidence, report writing and developing a plain English version of the guideline. In comparison, the Scottish Intercollegiate Guidelines Network (SIGN, 2006) consulted almost exclusively with health professionals and practitioners. Although this is a clinical guideline, it does cover approaches to care for people with dementia on which they would have been well placed to comment.

The National Dementia Strategy for England and Wales was published in 2009 (DH, 2009a) and during its development much care was taken to include as many stakeholders as possible. A series of working groups were held to develop the strategy. Each of these included one person with dementia and one or two current or former carers, although overall just two people with dementia, one former carer and three current carers were involved in these working groups $(\mathrm{DH}, 2008)$. It is not possible, from published literature, to ascertain the nature of the involvement of these individuals.

As well as the various working groups, many others were involved through 'listening and engagement events' in which over 3,000 people took part. The Alzheimer's Society was closely involved and held groups for people with dementia and their carers and distributed information through their branches. Information from all these sources was used to develop the strategy and the authors of the strategy note the consistency of the messages received from different stakeholders $(\mathrm{DH}, 2008)$. During the consultation process that followed 23 per cent of the 600 responses came from carers and 3 per cent from people with dementia ( $\mathrm{DH}, 2009 \mathrm{~b})$. Carers formed the largest group amongst respondents. The 3 per cent represents nineteen people with dementia. These processes suggest that every effort was made to ensure the views and opinions of people with dementia were incorporated in the strategy development, but there is little information available on the nature of their participation in the different fora.

Further evidence of the growing involvement and influence of people with dementia is the establishment of campaign groups formed by people with dementia. A high profile example is the Scottish Dementia Working Group (www.sdwg.org.uk) whose members are active in promoting better care and treatment for people with dementia through directly 
lobbying government, speaking at conferences; and developing educational products such as DVDs among many other activities.

This discussion illustrates willingness and enthusiasm among policy makers to include people with dementia and their carers. It is still the case, however, that the numbers of service users involved in policy planning groups are still very small and it is difficult to judge the effectiveness of this style of inclusion and the real benefits of user involvement for people with dementia to date. It is also not clear how representative those individuals involved are of the broader population of people with dementia. It may be that people in the earlier stages of the condition are more likely to be involved and their experiences and views may not reflect those of people with more advanced dementia.

\section{The consultation process in Fife}

In Fife, a range of techniques were adopted to encourage participation in the consultation process for the dementia strategy. A consultation document was prepared presenting the draft strategy and asking people to respond. The consultation document was made available in different forms: a full version, an abridged version, large type face was available on request or the strategy could be sent electronically. The document could be accessed through the Internet and local networks for social work, health and housing staff. In addition hard copies were posted to all independent sector care home providers. The main NGO working with people with dementia in the area was also closely involved. The consultation was advertised by placing posters in public places including post offices and GP surgeries. By the time of the consultation, many stakeholders within health and social work were aware of the strategy and helped disseminate the consultation document. Stakeholders in Fife were asked to comment on the proposed recommendations, actions and outcomes, and to help identify how each might be achieved. A detailed series of questions were provided to encourage focused responses.

At this time, the project team was aware that just a few people with dementia had been consulted directly during the development of the strategy and it seemed unlikely that many would respond to the written and internet calls for responses. It was, however, felt to be essential that people with dementia were included. To address this gap a series of group interviews were planned with people with dementia, other service users and carers.

The formal consultation took place over a six week period. In total 97 written and verbal responses were received from a broad range of stakeholders, including GPs, carers, social workers, nurses, care home workers, consultants from geriatrics and old age psychiatry, people with dementia and other people using the same services. A breakdown of responses is given in Figure 1.

\section{Consultation events with people with dementia and other service users}

A series of eight group interviews took place during the consultation involving fifty-six service users, fourteen of whom were identified by staff as people with dementia. The aim of these events was to enable people with dementia and other people using the same services to contribute their views on current services and on the strategy. To facilitate the inclusion of these individuals, the work of the project received approval from the relevant NHS Research Ethics Committee. 


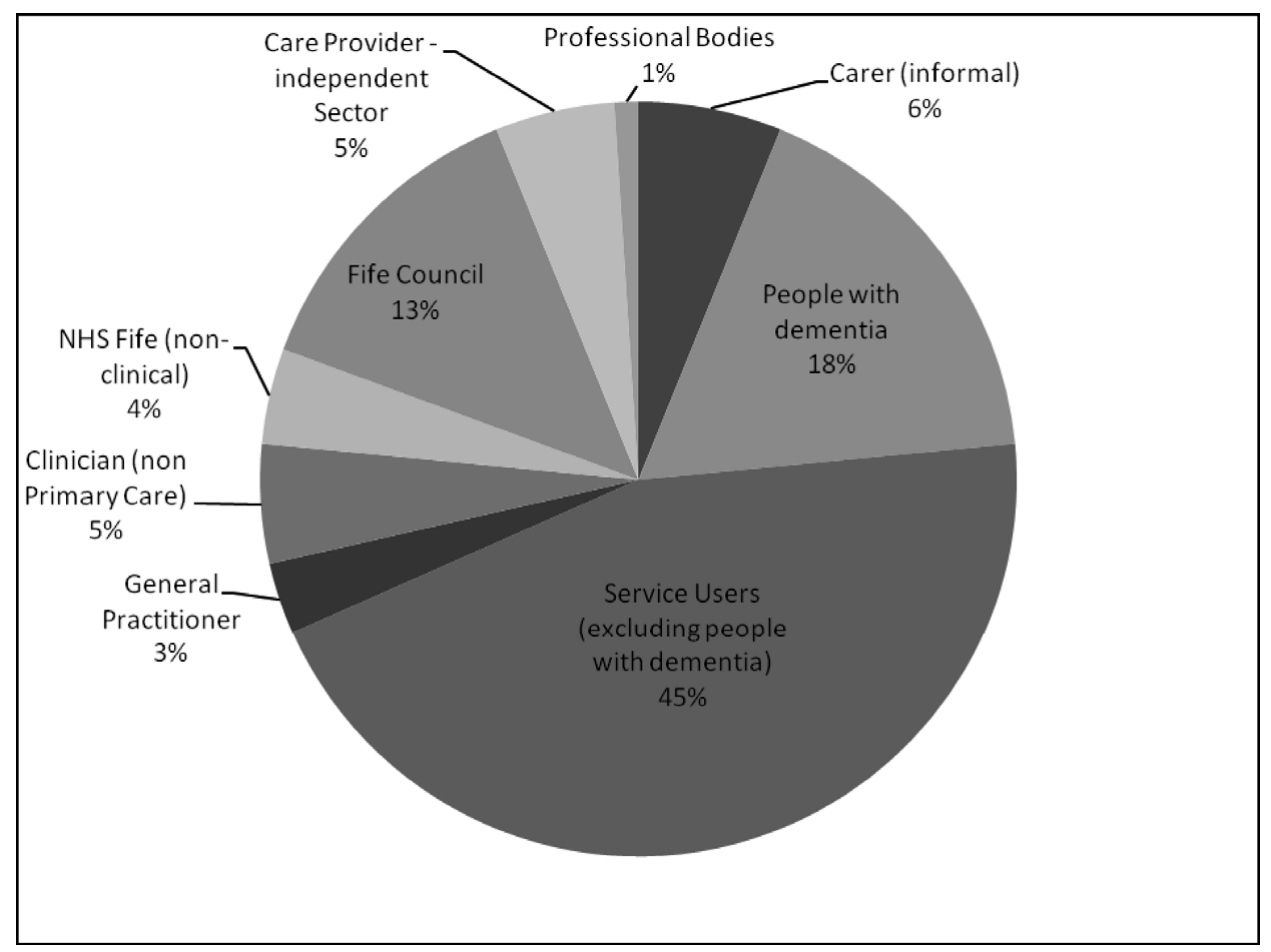

Figure 1. Public consultation response by category

Group interviews were used to facilitate inclusion of as many individuals as possible within a limited timeframe. It was also hoped that people with dementia would be more comfortable talking in a group of familiar people. Patmore, Qureshi and Nicholas (1999) found that older people preferred to be consulted on a one-to-one basis but group discussions were also found to be popular. It was felt important to take a research-like approach to encourage participation and ensure an ethical approach. The groups are described as group interviews rather than focus groups, although they followed the same structure. Focus groups are known to be effective fora for discussion on specific topics and provide good environments for sharing views and opinions (Bryman, 2008). However, focus groups are usually used to look at group dynamics and to study the interactions within the group (Bryman, 2008). In this case it was the opinions and knowledge of individuals which we were interested in rather than any interactions within the group.

Eight locations were chosen to represent a range of services used by people with dementia, including residential care, day care, and community settings, and to cover all regions within Fife. The group interviews were held in familiar settings for participants such as day centres or residential homes and most participants in each group were drawn from those settings. Qureshi et al., (1998) report that group discussions for older people work well in communal settings. Older people can find it difficult to travel to locations to take part in research (Thornton, 2000), so our approach used locations where potential participants were already present. Information sheets were sent in advance of the group interviews taking place. Invitations were issued to others, including carers, living close 
to each location and carers attended four of the groups. Within each setting, everyone present that day was told about the consultation process. Individuals who expressed an interest and who were able to give written consent were invited to participate and consent forms were signed by all participants. The groups ranged in size from seven to eleven participants. Each of the groups had a different mix of people with dementia, older service users, carers and care staff (see Appendix A for details).

The Fife strategy was structured to follow a hypothetical pathway of care for a person with dementia. Each section of the strategy covered a service or services relevant to each stage in the proposed pathway. These section titles were summarised to form a list of topics to be covered within the consultation with service users (a list of topics is given in Appendix B). Two or three topics were chosen from the list to be covered in each group according the expected experiences of participants. Often, however, groups covered a broader range of topics according to the interests of participants. Two researchers facilitated each group to support participation by everyone present. Participants appeared to enjoy the discussion and most took part. Care staff, where involved, often provided support and encouragement for people to participate, although at times they could talk over the service users.

The approach taken for these groups reflects good practice in research. As noted in the literature discussed above, the views and experiences of people with dementia seem to come through clearest in qualitative research where their involvement is facilitated in a carefully considered and ethical manner.

\section{Findings from the consultation}

Following the six week consultation, all responses were collated and analysed. Some responses provided support for existing strategy aims and others identified areas for change or development.

Raising awareness was identified by all stakeholders as an issue requiring more emphasis within the strategy. For clinicians this was about responding to recent research on risk and prevention. For people with dementia and other service users, there was a need for better access to information about dementia both for those already with a diagnosis and for those who were worried about dementia. Clinicians from primary care and from the acute hospital sector raised issues relating to frailty and the general health needs of people with dementia. A need was identified within the strategy to more directly address the role of general practitioners and clinical staff in general and acute health settings. Training was also highlighted as an area of importance across all sectors as was the need for better joint working. Frontline practitioners, people with dementia and other service users all identified the need for better transport provision; this came from people living in their own homes and from people living in care homes. Many of the suggestions received were in line with proposals within the strategy, just highlighting particular issues relevant to specific stakeholders.

\section{Views of people with dementia and other service users}

It is interesting to look separately at the views of people with dementia and other service users in order to compare and contrast these findings with those from all stakeholders and to give emphasis to their views. Four main themes were identified from the group 
interviews that recurred across the different groups and were reflected in discussions of all different service types. Firstly, service users spoke about where they lived and their attachment to 'home'. Secondly, they gave their views on the quality of the services they received. A third theme running through the interviews was that of 'getting out more.' The final theme reflected the desire of participants to better understand dementia.

Participants in the group interviews were overwhelmingly positive when speaking in general about the services they received, however they often went on to share stories of negative experiences. Many of the participants felt they did not know much about what services or support options were available and some felt 'lucky' to get what they did. Several did not want to receive services or had resisted support, and a number appeared to have low expectations of services. Participants did not talk about new models of care such as those promoted by personalisation, perhaps reflecting a lack of knowledge of available options. Despite this, most were grateful for and enjoyed the support they did receive. For many service users, the enjoyment was a result of the staff and the other service users. It was clear from these group interviews that participants felt people were the single most important factor in determining the quality of support received.

In many ways, the views of all stakeholders were similar, although professionals and practitioners included more specific comments, while people with dementia and other service users had more general views on the services they were currently receiving. This in part was due to the different approaches taken during the consultation exercise; people with dementia were asked more general questions rather than asked to comment specifically on the strategy (the draft strategy was a substantial document and it would not have been practical to ask individuals to respond to the whole document) and it was interesting to see how concerns matched across stakeholders. The wish to remain at home expressed strongly by service users is acknowledged in calls by other stakeholders for better care at home services and better integration of care homes into the community. When discussing quality of services, all were in agreement that current services could be improved, with people with dementia emphasising the need for frontline staff to have more time to spend with service users. The wish to get out more, expressed by people with dementia and other service users, would hopefully be met through professional concerns about the lack of suitable transport options.

Understanding more about dementia and the impact it has on people was a common discussion point in many of the group interviews and was also raised by other stakeholders. For professionals and practitioners, the importance of information was about the need for a public health message to promote prevention and reduce risk of dementia, but for service users this was a more personal concern relating to a need for information and support if they had a diagnosis of dementia or if they had concerns about themselves or others developing dementia. Many service users admitted an almost complete lack of knowledge about the symptoms of dementia and how it impacted on daily living. Most were keen to learn more, asking for information and resources, and listening to the experiences of others in their group.

Our findings mirror those of others who have consulted directly with people with dementia and older people with similar themes raised by participants concerning their lives and experiences of services (Thornton, 2000). For participants living at home, the concept of home was important and there is some evidence that individuals do better in terms of physical and mental well-being if they remain at home (Lansley, 2007). The positive views given of services and particularly the relationships with staff and other 
service users found here reflect the findings of Reid et al. (2001) in day care and Surr (2006) in residential care. However, in contrast, Clare et al. (2008b) and Graneheim and Jansson (2006) find more negative views of residential care among residents with dementia. Participants in this research who did not have experience of residential care were found to have negative views of the service but were interested to hear about the positive experiences of those who currently live in care homes. This suggests that more information about services that includes views of current service users would help people make decisions about their own care and support. Participants tended to talk about services and support they had experience of; newer approaches such as those framed as self-directed support where not something participants mentioned. This may be due to a lack of knowledge and experience of other options or perhaps due to gratitude for the support they do receive and a reluctance to suggest significant changes.

\section{Discussion}

The consultation process presented a challenge. It was important to get meaningful responses to the strategy and to engage with as broad a range of stakeholders as possible within a tight timescale. The strategy document was long and quite complex, addressing all aspects of care for people with dementia and presenting a ten-year plan for services. This made it difficult for some stakeholders to engage with consultation process; it took a significant investment of time to read and comment on the strategy for even the most committed practitioners. Our mixed approach to the consultation, as outlined in this article, reflected that of national dementia strategies, such as those published in England and Scotland (DH, 2009a; Scottish Government, 2010) where a range of approaches were taken during the consultation phase. This enabled a wide range of stakeholders to engage with the consultation process.

\section{How the consultation impacted on the strategy}

The value of this consultation exercise cannot be underestimated. It helped to identify topics that had been missed or not clearly understood by the project team. It also helped to prioritise recommendations and actions within the strategy to reflect current need. Specific examples are given below of how consultation influenced the strategy.

The public consultation document was generally well received across Fife. The recommendations and actions for improving dementia services were thought to be largely the right ones, and the layout of the strategy was well regarded. However, there were a series of suggestions made by people on how the strategy could be improved. Some suggestions were too specific to individual services and were omitted as the strategy did not have the scope to make recommendations at this level. Some general changes were made to the strategy to reflect feedback and alter the emphasis to be more inclusive of generalist services. One key change was that the words of service users and providers were added to the strategy to add context and illustrate key points.

In addition to minor changes made to the strategy, key changes made as a result of the public consultation included: ensuring dementia awareness campaigns include messages about the importance of a healthy lifestyle in reducing risk of dementia; addition of a section on improving approaches to general health care; ensuring that any electronic care management system is developed through the integration of current systems rather than 
the creation of new ones; recognising potential conflicts in needs between carers and the cared for; the importance of advocacy services; addition of actions targeted at improving transport options; and changes in the intermediate care section to ensure a proactive approach is taken in the provision of generalist and specialist services. In addition, a significant number of comments were received regarding the challenges of implementing the strategy and in response to this the appointment of individual leads within health and social work was recommended. Changes to the strategy made directly in response to comments from people with dementia and other service users included highlighting ways to improve communication between service users and providers; improving transport options available; increasing the number of opportunities for people to get out more; improving the availability of information among the general public; and better integration of care homes into local communities. Service users highlighted important issues that had been missed or addressed inadequately in the strategy. The issues raised by service users also helped to prioritise issues within the timeline for implementation of the strategy.

\section{Involving people with dementia and other service users}

It was found that people with dementia were able to meaningfully contribute to the strategy development, as found by others developing policy (for example, Gould and Kendall, 2007). The group interviews were a crucial stage in the consultation process for a number of reasons relating to benefits for the strategy team and the strategy itself as well as broader benefits relating to understandings of the experiences of people with dementia.

It was found that the inclusion of the views of people with dementia helped to gain support for the strategy and aided implementation. Their voices added validity and credibility to the strategy document. As Carey (2009) notes, there are clear benefits to organisations from user involvement. Another benefit was increased understanding of the views and experiences of service users. The findings from the group interviews were disseminated in a range of ways, for example, they were presented at the strategy launch event which was attended by over one hundred local professionals and practitioners.

The reasons discussed so far are not directly about the people with dementia and other service users who were included in the consultation. The group interviews provided a forum for these groups to effectively contribute to the strategy development and to ensure that the plans being made led to care and services that are useful for them. It is very important to ensure that the voices of these marginalised groups are clearly heard within the development of policy that directly impacts on their lives. As well as promoting user involvement, in line with government objectives, supporting participation is about promoting social inclusion and citizenship. If people with dementia are considered within a citizenship model then the focus moves away from care and treatment towards promoting and supporting their inclusion in society (Bartlett and O'Connor, 2007; Baldwin, 2008). Citizenship is about being 'full members of a community' (Marshall, 1949: 18) and participation in the development of local policy is one example of fulfilling this aim for people with dementia.

Citizenship implies agency but people with dementia may not always have access to the resources required to 'participate' thus it is important to reflect on who is involved in consultation and research. Some of the people with dementia we met limited their 
participation to nods in agreement to others while others were active contributors to the discussions. For the first group, it seems unlikely that they would be comfortable participating in the types of working groups and committees regularly used to develop policy and practice guidelines. Bartlett and O'Connor (2007) caution that promoting citizenship for people with dementia can lead to further exclusion for many people who may find it difficult or who are unable to participate in particular fora. Similarly, Craig (2004) argues for a different understanding of citizenship for older people that takes account of the ways in which they are involved with and contribute to wider society. The examples of research discussed earlier in this article (e.g. Steeman et al., 2007; Clare et al., 2008a) more often use one to one interviews and these may provide a better approach to eliciting the views of people with dementia who find it difficult to contribute to group discussions due to a lack of confidence, difficulties with communication or any other reason. The drawback of using one to one interviews is that they are time consuming and may limit the number of people included. This approach sought to find a middle ground where people with dementia could share their views in familiar surroundings and where the views of as many people as possible could be included in the short time available. The approach described here supported people with dementia and other older service users to act as citizens and influence policy within their local area.

\section{Conclusion}

This article has presented the process and outcomes of consultation on a local policy, the Fife Dementia Strategy. This process was challenging as it aimed to involve a broad range of stakeholders, commenting on a long and complex policy document in a relatively short time frame, just six weeks. This consultation process was, however, essential in the development of the strategy. It ensured that the strategy was relevant in the local context and appropriate for current local systems. It promoted engagement from a broad range of professionals and practitioners encouraging their ongoing support for the strategy. The consultation exercise also sought to promote user involvement in the process of local policy development by directly engaging with people with dementia and encouraging their participation. The process of user involvement benefitted the organisations developing the strategy by strengthening and validating the strategy aims and objectives but more importantly this process helped to promote inclusion and citizenship for people with dementia and other service users who are often marginalised within the policy making process.

\section{References}

Agnew, A. and Duffy, J. (2010) 'Innovative approaches to involving service users in palliative care', Social Work Education, 29, 7, 744-59.

Alzheimer's Society (2009) Out of the Shadows, London: Alzheimer's Society, http://www.alzheimers.org. uk/site/scripts/download_info.php?downloadID $=133 \&$ filelD $=454$.

Baldwin, C. (2008) 'Narrative, citizenship and dementia: the personal and the political', Journal of Aging Studies, 22, 222-8.

Bartlett, R. and O'Connor, D. (2007) 'From personhood to citizenship: broadening the lens for dementia practice and research', Journal of Aging Studies, 21, 107-18.

Beard, R. and Fox, P. (2008) 'Resisting social disenfranchisement: negotiating collective identities and everyday life with memory loss', Social Science and Medicine, 656, 1509-20. 
Beresford, P. (2010) 'Public partnerships, governance and user involvement: a service user perspective', International Journal of Consumer Studies, 34, 5, 495-502.

Bryman, A. (2008) Social Research Methods, 3rd edn, Oxford: Oxford University Press.

Carey, M. (2009) 'Happy shopper? The problem with service user and carer participation', British Journal of Social Work, 39, 1, 179-88.

Clare, L. (2002) 'We'll fight it as long as we can: coping with the onset of Alzheimer's disease', Aging and Mental Health, 6, 2, 139-48.

Clare, L., Roth, I. and Pratt, R. (2005) 'Perceptions of change over time in early-stage Alzheimer's disease', Dementia, 4, 4, 487-520.

Clare, L., Rowlands, J., Bruce, E., Surr, C. and Downs, M. (2008a) 'I don't do like I used to do': a grounded theory approach to conceptualizing awareness in people with moderate to severe dementia living in long term care', Social Science and Medicine, 66, 11, 2366-77.

Clare, L., Rowlands, J., Bruce, E., Surr, C. and Downs, M. (2008b) 'The experience of living with dementia in residential care: an interpretive phenomenological analysis', The Gerontologist, 48, 6, 711-20.

Craig, G. (2004) 'Citizenship, exclusion and older people', Journal of Social Policy, 33, 1, 95-114.

DeBaggio, T. (2002) Losing My Mind: An Intimate Look at Life with Alzheimer's, New York: The Free Press.

Department of Health (2006) Our Health, Our Care, Our Say, London: Department of Health, http://www. dh.gov.uk/en/Publicationsandstatistics/Publications/PublicationsPolicyAndGuidance/DH_4127453.

Department of Health (2009a) Living Well with Dementia, London: Department of Health, http://www.dh. gov.uk/en/socialcare/deliveringadultsocialcare/olderpeople/nationaldementiastrategy/index.htm.

Department of Health (2009b) Consultation Response and Analysis National Dementia Strategy, London: Department of Health, http://www.dh.gov.uk/en/Consultations/ Responsestoconsultations/DH_094059.

Department of Health (2010) A Vision for Adult Social Care: Capable Communities and Active Citizens, London: Department of Health, http://www.dh.gov.uk/en/ Publicationsandstatistics/Publications/PublicationsPolicyAndGuidance/DH_121508.

Department of Health (2008) Transforming the Quality of Dementia Care, Consultation on a National Dementia Strategy, London: Department of Health, http://www.dh.gov.uk/ prod_consum_dh/groups/dh_digitalassets/documents/digitalasset/dh_085567.pdf.

Gould, N. and Kendall, T. (2007) 'Developing the NICE/SCIE guidelines for dementia care: the challenges of enhancing the evidence base for social and health care', British Journal of Social Work, 37, 475-90.

Graneheim, U. and Jansson, L. (2006) 'The meaning of living with dementia and disturbing behaviour as narrated by three persons admitted to a residential home', Journal of Clinical Nursing, 15, 1397-403.

Keady, J. and Gilliard, J. (2002) 'Testing times: the experience of neuropsychological assessment for people with suspected Alzheimer's', in P. Braudy Harris (ed.), The Person with Alzheimer's Disease: Pathways to Understanding the Experience, Baltimore: John Hopkins University Press.

Keady, J., Williams, S. and Hughes-Roberts, J. (2009) 'Analysing decision making: bridging and balancing', in D. O'Connor and B. Purves (eds.), Decision-Making, Personhood and Dementia, London: Jessica Kingsley Publishers.

Langdon, S., Eagle, A. and Warner, J. (2007), 'Making sense of dementia in the social world: a qualitative study', Social Science and Medicine, 64, 989-1000.

Lansley, P. (2007) 'Assistive Technology and Older People: A broad Perspective', Irish Ageing Studies Review, seminar proceedings on independent living, available at http://www.gerontology.ie/ documents/IGS_Journal_Vol1_07.pdf

Macquarrie, C. (2005) 'Experiences in early stage Alzheimer's disease: understanding the paradox of acceptance and denial', Aging and Mental Health, 9, 5, 430-41.

Marshall, T. H. (1949/92) 'Citizenship and social class', in T. H. Marshall and T. Bottomore (eds.), Citizenship and Social Class, London: Pluto Press, pp. 3-51.

Mobley, T. (2007) Young Home: The Broken Road, Denver: Outskirts Press.

National Institute of Clinical Excellence (NICE) and Social Care Institute for Excellence (SCIE) (2006) Dementia: Supporting People with Dementia and Their Carers in Health

\section{CAMBRIDGE JDURNALS}


and Social Care, NICE Clinical Guideline 42, London: NICE/SCIE, http://www.scie.org.uk/ publications/misc/dementia/dementia-guideline.pdf.

Norwegian Ministry of Health and Care Services (2008) Dementia Plan 2015, Oslo: Norwegian Ministry of Health and Care Services.

Patmore, C., Qureshi, H. and Nicholas, E. (1999) 'Tuning into feedback', Community Care, 24-30, June, 28-9.

Qureshi, H., Patmore, C., Nicholas, E. and Bamford, C. (1998) 'Overview: outcomes of social care for older people and carers', Outcomes in Community Care Practice, No. 5, York: Social Policy Research Unit, University of York.

Reid, D., Ryan, T. and Enderby, P. (2001) 'What does it mean to listen to people with dementia', Disability and Society, 16, 3, 377-92.

Reynish, E. (2009) 'Prevalence of dementia in Europe, results from the EuroCoDe project', Presentation at the Alzheimer Europe conference, Brussels.

Scottish Government (2010) Scotland's National Dementia Strategy, Edinburgh: Scottish Government, http://www.scotland.gov.uk/Publications/2010/09/10151751/17.

Scottish Government (2009) Changing Lives: Personalisation - A Shared Understanding. Commissioning for Personalisation: A Personalised Commissioning Approach to Support and Care Services. Edinburgh: Scottish Government, http://www.scotland.gov.uk/ Publications/2009/04/07112629/0.

Secretary of State for Health (2009) Shaping the future of care together (Cm7673), London: The Stationery Office.

SIGN (2006) Management of Patients with Dementia, Guide 86, Edinburgh: Scottish Intercollegiate Guidelines Network, http://www.sign.ac.uk/pdf/sign86.pdf.

Steeman, E., Godderis, J., Grypdonck, M. et al. (2007) 'Living with dementia from the perspective of older people: is it a positive story?', Aging and Mental Health, 11, 2, 119-30.

Surr, C. (2006) 'Preservation of self in people with dementia living in residential care: a socio-biographical approach', Social Science and Medicine, 62, 1720-30.

Thornton, P. (2000) Older People Speaking Out: Developing Opportunities for Influence, York: Joseph Rowntree Foundation.

Ward, R., Vass, A., Aggarwal, N. et al. (2008) 'A different story: exploring patterns of communication in residential dementia care', Ageing and Society, 28, 629-51.

\section{Appendix A. Membership of group interviews}

\begin{tabular}{lcclll}
\hline \hline Location & $\begin{array}{l}\text { Total number of } \\
\text { participants }\end{array}$ & $\begin{array}{l}\text { People with } \\
\text { dementia }\end{array}$ & $\begin{array}{l}\text { Other service } \\
\text { users }\end{array}$ & $\begin{array}{l}\text { Staff } \\
\text { members }\end{array}$ & $\begin{array}{l}\text { Informal } \\
\text { carers }\end{array}$ \\
\hline $\begin{array}{l}\text { Residential care } \\
\text { home }\end{array}$ & 8 & 2 & 5 & 1 & 0 \\
$\begin{array}{l}\text { Day centre } \\
\text { Day centre }\end{array}$ & 10 & 3 & 5 & 2 & 0 \\
Day centre & 7 & 1 & 6 & 0 & 0 \\
Day centre & 11 & 2 & 6 & 0 & 0 \\
$\begin{array}{l}\text { Day centre } \\
\text { Younger persons }\end{array}$ & 11 & 2 & 5 & 2 & 2 \\
$\quad 7$ & 2 & 7 & 1 & 1 \\
$\quad$ specialist & & 2 & 1 & 3 & 1 \\
$\quad$ dementia day & & & & & \\
centre & & & & & \\
Tommunity centre & 8 & 0 & 7 & 9 & 1 \\
\hline \hline
\end{tabular}




\section{Appendix B. List of topics covered in focus groups}

- Assessment, diagnosis and referral

- Housing

- Community care including day care

- Home care

- Short breaks

- Primary care

- Acute care

- Residential care

- Palliative and end of life care

- Emergency services

- Early onset special issues

- Legislation

- General awareness of dementia

\section{CAMBRIDGE JOURNALS}

